\title{
Nitrogen dioxide and mortality: review and meta-analysis of long-term studies
}

Annunziata Faustini ${ }^{1}$, Regula Rapp ${ }^{2}$, Francesco Forastiere ${ }^{1}$

${ }^{1}$ Dept. of Epidemiology, Regional Health Service, Lazio Region, Rome, Italy

${ }^{2}$ Swiss Tropical and Public Health Institute, Basel, Switzerland

Correspondence to:

Dr A Faustini, Department of Epidemiology, Regional Health Service of Lazio,

V. S. Costanza, 53,

00198 Rome

Italy

Tel. 0039/06/83060440 e-mail a.faustini@ deplazio.it

Fax 0039/06/83060463

Abstract: words $=213$

Text: words $=4065$

Tables + Figures $=5$

References $=38$ 


\section{Abstract}

Background. Exposure to ambient nitrogen dioxide $\left(\mathrm{NO}_{2}\right)$ has been linked to increased mortality in several epidemiological studies but the question remains of whether $\mathrm{NO}_{2}$ is directly responsible for the health effects, or is only an indicator of other pollutants, including particulate matter (PM).

Aim. To provide pooled estimates of the long-term effects of $\mathrm{NO}_{2}$ on mortality, potentially useful for health impact assessment.

Methods. We selected 23 papers, published from 2004 to 2013, evaluating the relationship between $\mathrm{NO}_{2}$ and mortality, also including an assessment of the effect of PM exposure. A random effects meta-analysis was carried out on 19 studies.

Results. The pooled effect on mortality was $1.04(95 \%$ confidence intervals $(\mathrm{CI})=1.02-1.06)$, with an increase of $10 \mu \mathrm{g} / \mathrm{m}^{3}$ in the annual $\mathrm{NO}_{2}$ concentration, and 1.05 (95\% $\left.\mathrm{CI}=1.01-1.09\right)$ for $\mathrm{PM}_{2.5}$ $\left(10 \mu \mathrm{g} / \mathrm{m}^{3}\right)$. The effect on cardiovascular mortality was $1.13(95 \% \mathrm{CI}=1.09-1.18)$ for $\mathrm{NO}_{2}$ and 1.20 (95\% CI=1.09-1.31) for $\mathrm{PM}_{2.5}$. The $\mathrm{NO}_{2}$ effect on respiratory mortality was $1.03(95 \% \mathrm{CI}=1.02-$ 1.03) and 1.05 (95\% CI 1.01-1.09) for $\mathrm{PM}_{2.5}$. Four bi-pollutant analyses with $\mathrm{PM}$ and $\mathrm{NO}_{2}$ in the same models showed minimal changes in the effect estimates of $\mathrm{NO}_{2}$.

Conclusions. There is evidence of a long-term effect of $\mathrm{NO}_{2}$ on mortality as great as that of $\mathrm{PM}_{2.5}$. An independent effect of $\mathrm{NO}_{2}$ emerged from multi-pollutant models.

Key words: air pollution, long-term $\mathrm{NO}_{2}$ and $\mathrm{PM}_{2.5}$ exposure, natural mortality, cause-specific mortality, systematic review, meta-analysis.

Running head: long-term $\mathrm{NO}_{2}$ exposure and mortality

The most important message of our study: Any health impact assessment overlooking $\mathrm{NO}_{2}$ would neglect some adverse effects of today's air pollution mixture. 


\section{Introduction}

The long-term effects on mortality of exposure to nitrogen dioxide $\left(\mathrm{NO}_{2}\right)$ were assessed in the WHO Air Quality Guidelines in 2005 [1] and the overall evidence was considered limited, given the small number of studies available. Neither the development of chronic diseases nor lung cancer was clearly associated with nitrogen dioxide in any of the studies taken into consideration in the 2005 WHO report. On the other hand, short-term mortality studies, studies of the impairment of lung function growth in children, and investigations of recurrent respiratory problems all suggested that there was evidence of a $\mathrm{NO}_{2}$ effect. Recent documents on traffic exposure from the American Thoracic Society [2] and the Health Effect Institute [3] considered $\mathrm{NO}_{2}$, among other traffic-related pollutants, and concluded that there is evidence suggesting that these pollutants have a causal role on mortality and on the development of chronic respiratory diseases.

The recent review of the health effects of air pollution by a WHO working group (Review of evidence on health aspects of air pollution - the REVIHAAP project) [4] evaluated the most recent studies on long-term exposure to $\mathrm{NO}_{2}$ and both natural (non-accidental)/total and cause-specific mortality. The question of whether $\mathrm{NO}_{2}$ is directly responsible for the health effects or is only an indicator of other pollutants - including particulate matter (PM) and specific constituents such as metals, polycyclic aromatic hydrocarbons and other organic matter - was specifically considered. The conclusion was that it is difficult "to judge the independent effects of $\mathrm{NO}_{2}$ in the long-term studies because, in those investigations, the correlations between concentrations of $\mathrm{NO}_{2}$ and other pollutants are often high, so that $\mathrm{NO}_{2}$ might represent a mixture. In this case, chamber studies do not apply and toxicological evidence is limited. However, some epidemiological studies do suggest associations of long-term $\mathrm{NO}_{2}$ exposures with respiratory and cardiovascular mortality and with children's respiratory symptoms and lung function that were independent of PM mass metrics. As with the short-term effects, $\mathrm{NO}_{2}$ in these studies may represent other constituents. Despite this, the mechanistic evidence, particularly on respiratory effects, and the weight of evidence on short-term 
associations suggest a causal relationship.” In other words, the WHO working group suggested that the response to the causality question cannot be derived only from the epidemiological studies but requires the integration of exposure science, toxicology, and human studies.

At the time of the REVIHAAP project, a quantitative systematic review of the long-term effects on mortality of $\mathrm{NO}_{2}$ was not available. A subsequent review by Hoek et al. [5], considering the association between several pollutants and long-term mortality, showed a significant association of all-cause mortality with $\mathrm{NO}_{2}$ in 15 longitudinal studies. Their work did not permit comparison of the effects of $\mathrm{NO}_{2}$ with those of other pollutants, namely particulate matter (PM), when the same studies were considered or when the results of the multi-pollutant models were available.

To contribute to the discussion about the role of $\mathrm{NO}_{2}$ from an epidemiological perspective, and to provide pooled estimates of the long-term effects of $\mathrm{NO}_{2}$ on mortality, potentially useful for assessing the health impact of air pollution, we systematically examined the studies that investigated the long-term effects on mortality of both outdoor $\mathrm{NO}_{2}$ and particles in the same population, and carried out a meta-analysis of both $\mathrm{NO}_{2}$ and $\mathrm{PM}$ effects.

\section{MeThods}

\section{$\underline{\text { Systematic review }}$}

The search strategy focused on studies reporting $\mathrm{NO}_{2}$ (or $\mathrm{NOx}$ ) effects on total and specific-cause mortality. The databases PubMed, Web of Science, and LUDOK were searched. The search was restricted to the period from January 2004 - January 2013 and to humans. Search terms were: nitrogen dioxide (as nitrogen dioxide/adverse effects MESH in PubMed, and as nitrogen oxides in LUDOK), together with cohort study or case-control study, and together with mortality, cardiovascular $(\mathrm{CV})$ mortality and respiratory mortality.

Articles were included if long-term effects on natural/total or specific (cardio-vascular or respiratory) mortality were assessed and the estimates of association with the pollutants were 
reported; the exposure needed to have been measured as at least an annual mean concentration in the study area. Papers were excluded when short-term effects were estimated, no health effect was measured, incidence or prevalence was assessed, no original data were analysed and, finally, when no control for confounding due to individual factors was carried out. Reviews and methodological papers were excluded as well. Studies carried out on groups restricted to at-risk people were, however, not excluded.

The first screening of the papers was carried out by checking the titles and the abstracts. The texts of the remaining papers were read in full, so as to select those that also included effect estimates for particles with a diameter $<10$ micron $\left(\mathrm{PM}_{10}\right)$ or with a diameter $<2.5$ micron $\left(\mathrm{PM}_{2.5}\right)$, total suspended particles (TSP) and black smoke (BS)).

The following characteristics were reported for each paper: authors, location and year of publication; study population; study design and study period (including both the enrolment and the follow-up period, if it was required by the study design); exposure assessment, including the method employed to assess levels, the mean concentration of pollutants and their exposure metrics; traffic exposure indicators (such as distance from the nearest high-traffic road, traffic density (TD), etc.); effect estimates on both total and specific-cause mortality.

\section{$\underline{\text { Meta-analysis }}$}

Before pooling data, we converted the effect estimates related to $\mathrm{NOx}$ into $\mathrm{NO}_{2}$ effects, using a conversion factor of 0.75 [6]; the $\mathrm{NO}_{2}$ concentrations expressed in $\mathrm{ppb}$ were converted into $\mu \mathrm{g} / \mathrm{m}^{3}$; we used a conversion factor of 1.88 (at $25^{\circ} \mathrm{C}$ and $1013 \mathrm{mb}$ ) for both $\mathrm{NO}_{2}$ and $\mathrm{NOx}$. The effects related to TSP were converted into $\mathrm{PM}_{10}$ effects, using a factor of 0.75 [7], and the effects related to $\mathrm{PM}_{10}$ were converted into $\mathrm{PM}_{2.5}$ effects, using a factor of 0.7 [8]. Diesel particulate matter (DPM) and BS were analysed as indicators of $\mathrm{PM}_{2.5}$. [9] In addition, the effects expressed as interquartile (or quintile or percentile) differences were converted into effects of a $10 \mu \mathrm{g} / \mathrm{m}^{3}$ increase of each pollutant. 
We used hazard ratios (HR), odds ratios (ORs) and relative risks (RRs) of mortality in a random effects meta-analysis [10] (Stata, version 10), thus including the risk estimates in the pooled analysis irrespective of the study design. The risk estimates and 95\% confidence intervals (CI) from each study were reported, having been adjusted for all the factors the authors assessed as confounders. The standard error (SE) of the effect was calculated from the risk estimates and the confidence intervals $(\mathrm{SE}=(\ln \mathrm{RR}-\ln$ lowest limit $\mathrm{CI}) / 1.96$ or $\mathrm{SE}=(\ln$ highest limit $\mathrm{CI}-\ln$ RR)1.96). The random pooled effects were reported as hazard ratios (HR), since most studies used Cox's survival analysis. We assessed heterogeneity across studies by using the $\chi^{2}$ test (Cochran's Q) and the $\mathrm{I}^{2}$ [11], which represents the proportion of total variation in effect estimates due to heterogeneity between the studies. Finally, we stratified the results by geographical area (Asia, North America, Europe).

To compare the relative effects of $\mathrm{NO}_{2}$ and $\mathrm{PM}_{2.5}$, we carried out a meta-analysis, using the interquartile range (IQR) as the exposure metric instead of the fixed increment $\left(10 \mu \mathrm{g} / \mathrm{m}^{3}\right)$. We included only studies where the IQRs were available or could be derived by using the mean concentrations and their standard deviations. The pooled estimate was obtained for a median IQR of all the single IQRs from those reported or specifically estimated.

\section{RESULTS}

Our initial search led to the selection of a total of 180 papers that were seen to deal with $\mathrm{NO}_{2}$ (or NOx) exposure. We excluded 146 papers on the basis of their titles and abstracts: 9 reviews and a further 12 papers which did not analyse original data; 2 methodological studies and 8 with study designs that made it impossible to adjust for individual confounders, 33 papers which did not assess health effects or human outcomes, 46 papers dealing with short-term effects, 26 papers with longterm effects other than mortality, and 9 papers with a mean exposure to air pollution considered for less than one year. Thereafter, from the 34 studies that had been identified as warranting reading in full, we selected 23 studies [12-34] which assessed PM effect in addition to $\mathrm{NO}_{2}$ or NOx effects. All 
the selected studies and their characteristics are reported in detail in supplemental Table A. The 11 excluded studies are listed in supplemental Table B.

Fourteen studies $[12,13,17,19,20-24,26,30-32,34]$ evaluated natural or total mortality; 17 studies $[12,13,15,17-20,22,23,25,26-29,32-34]$ considered cardiovascular mortality (including four studies [13, 23, 32, 34] assessing cardio-pulmonary mortality); 14 studies considered respiratory mortality $[12-14,16,17,19,20,22,23,26,28,32,34]$ (including the four with cardiopulmonary mortality as a single outcome, $[13,23,32,34]$ and a further one [14] which assessed lung cancer and respiratory mortality as a single outcome). Only ten studies [12, 13, 17, 19, 20, 22, $23,26,32,34]$ evaluated both total and cause-specific mortality, though data were not always exhaustively reported. There were 21 cohort studies [12-24, 26-28, 30-34] and two case-control studies [25, 29].

Cohort studies involved adults of both sexes, but one paper selected only adult men [20] and four selected only adult women [13,19,27,32], and two further paper [28, 33] studied both men and women but separately. Among the other studies, one studied only women [29]. Five studies focused on specific at-risk groups: patients with stroke [21], respiratory diseases [22], hypertension [24] and first myocardial infarction $[25,29]$.

Several confounders were assessed in each paper. Sex, age and social class (identified by different indicators such as education, deprivation index, occupation, area-level socio-economic-position (SEP) or income) were included in most studies. Only Dong, [14] Katanoda [16] and Lipfert [24] included no SEP indicator in their final analysis. Habitual smoking was frequently adjusted for [1517, 21, 26, 27, 32, 33], whereas co-morbidities were rarely assessed [12,18,21].

Asia was represented by four studies: one from Japan and three from China; North America contributed nine studies: two from Canada and seven from the U.S.A., and Europe contributed 10 studies. 
$\mathrm{NO}_{2}$ was a main exposure in almost all studies, but two $[17,24]$ used NOx. The exposure metric was mostly expressed in $\mu \mathrm{g} / \mathrm{m}^{3}$ of $\mathrm{NO}_{2}$, but one study from Asia [16], one from Canada [22] and all seven studies from the U.S.A. [19, 20, 23, 24, 30, 31, 33] reported the mean levels of $\mathrm{NO}_{2}$ in ppb. The unit increase of $\mathrm{NO}_{2}$ was usually reported (16 studies from all the geographic areas) as interquartile or centile range rather than as $10 \mu \mathrm{g} / \mathrm{m}^{3}[12,13,18-20,22-25,26-29,31-33]$. The mean yearly level of $\mathrm{NO}_{2}$ was $41.6 \mu \mathrm{g} / \mathrm{m}^{3}$ in Asia, $42.2 \mu \mathrm{g} / \mathrm{m}^{3}$ in North America, and 36.2 $\mu \mathrm{g} / \mathrm{m}^{3}$ in Europe.

Particulate matter was studied for the most part as $\mathrm{PM}_{10}$ (11 studies) [13-15, 19-21, 25, 27-29, 32] with the effect estimated for $10 \mu \mathrm{g} / \mathrm{m}^{3}$ (5 studies), and otherwise as IQR, expressed in $\mu \mathrm{g} / \mathrm{m}^{3} . \mathrm{PM}_{2.5}$ was studied in 11 cases [12, 16, 18, 22-24, 26, 30, 31, 33, 34] with exposure expressed most frequently as an IQR increase of concentrations (six studies). Total suspended particles (expressed in $10 \mu \mathrm{g} / \mathrm{m}^{3}$ ) was the particle metric in one study [17]. The mean yearly level of $\mathrm{PM}_{2.5}$ was 87.4 $\mu \mathrm{g} / \mathrm{m}^{3}$ in Asia, $14.8 \mu \mathrm{g} / \mathrm{m}^{3}$ in North America, and $25.4 \mu \mathrm{g} / \mathrm{m}^{3}$ in Europe.

The correlation between $\mathrm{NO}_{2}$ (or $\mathrm{NOx}$ ) and $\mathrm{PM}_{10}$ was reported in 8 studies out of 11 , with values ranging from 0.5 [13] to $0.9[14,15,29]$. The correlation between $\mathrm{NO}_{2}$ and $\mathrm{PM}_{2.5}$ was reported in 9 studies out of 11 , with values ranging from 0.3 in the Japanese study [16] and in the California study [33] to 0.88 in the Norwegian study [28]. The study using only TSP [17] did not indicate the correlation with $\mathrm{NO}_{2}$.

Traffic exposure indicators were reported in nine publications. Two evaluated proximity to a road with heavy traffic and traffic density [12,26], the studies in Toronto [22] and in Germany (the SALIA cohort study) $[13,27,32]$ investigated only proximity to traffic, and the U.S. Veterans studies [24,30,31] evaluated traffic density only.

We included 19 studies in the meta-analysis. Four of the 23 included in the systematic review have been further excluded from the meta-analysis since three of them reported more complete analyses 
three years later [29-31] and one other [14] reported mortality only for respiratory diseases and lung cancer as a single outcome. In contrast, two of the included papers $[28,33]$ carried out separate analyses for men and women, thus producing 21 effect estimates actually analysed.

The pooled estimate of natural/total mortality was performed for 12 studies [12, 13, 17, 19-24, 26, $32,34]$, the pooled estimate of cardiovascular mortality made use of 18 effect estimates $[12,13,15$, 17-20, 22, 23, 25, 26, 27, 28 (men), 28 (women), 32, 33 (men), 33 (women), 34], the meta-analytic estimate of respiratory mortality included 9 effect estimates [12, 16, 17, 19, 20, 22, 26, 27 (men), 27 (women)].

The pooled estimate of $\mathrm{NO}_{2}$ effects on natural/total mortality (Table 1; Figure 1) was 1.04 (95\%CI $=1.02-1.06)$ per $10 \mu \mathrm{g} \mathrm{NO}_{2} / \mathrm{m}^{3}$ and the corresponding effect of $\mathrm{PM}_{2.5}$ was $1.05(95 \% \mathrm{CI}=1.01-$ 1.09) per $10 \mu \mathrm{g} / \mathrm{m}^{3}$. However, there was high heterogeneity across the studies in North America, the $\mathrm{NO}_{2}$ effects were not statistically significant while the effects of $\mathrm{PM}_{2.5}$ were larger and statistically significant (in spite of the fact that the levels of $\mathrm{PM}_{2.5}$ observed there were the lowest we found). The greatest effect on natural/total mortality was observed in Europe for both $\mathrm{NO}_{2}$ and $\mathrm{PM}_{2.5}$, but heterogeneity observed across the studies was still high. It should be noticed that a part of this heterogeneity could be explained by just one study [21] on stroke patients.

The pooled estimate of the $\mathrm{NO}_{2}$ effect (Table 1; Figure 2) on cardiovascular mortality was 1.13 $(95 \% \mathrm{CI}=1.09-1.18)$, while the effect of $\mathrm{PM}_{2.5}$ was $1.20(95 \% \mathrm{CI}=1.09-1.31)$, per $10 \mu \mathrm{g} / \mathrm{m}^{3}$ of each pollutant. In Asia, the effects of both $\mathrm{NO}_{2}$ and $\mathrm{PM}_{2.5}$ were greater than those in North America and Europe. Notably, the results were affected by high heterogeneity in all areas. In Asia, where the overall $\mathrm{NO}_{2}$ estimate did not attain statistical significance (and heterogeneity showed values near 99\%), one study [15] provided very high effect estimates, much greater than for the other studies. In North America, the study in Toronto [22], carried out on patients from a respiratory clinic, provided effects on cardiovascular mortality as high as $64 \%$ for $\mathrm{NO}_{2}$, in contrast with a mean increase of $1 \%$ in the other studies. 
To better evaluate the heterogeneity of the pooled effect estimates of $\mathrm{NO}_{2}$ on total and cardiovascular mortality, we conducted subgroup analyses considering studies not involving at-risk groups [excluding references 21, 22, 24, 25] and studies with better exposure assessment (land use regression, dispersion models, or other methods at the address level) [12, 18-22, 25, 26, 28]. The heterogeneity of the effects generally remained in these subgroups when they were considered separately (supplemental table D). However, when we restricted to studies conducted in the general population (not on at-risk groups) and with a better exposure assessment, the heterogeneity for cardiovascular mortality decreased ( $\mathrm{p}$-value $=0.690$ and $\mathrm{I}^{2}=0 \%$, based on 7 studies) corresponding to an effect estimate of 1.03 for $\mathrm{NO}_{2}$.

The pooled estimate of $\mathrm{NO}_{2}$ effects (Table 1 ; Figure 3$)$ on respiratory mortality was $1.02(95 \% \mathrm{CI}=$ 1.02-1.03) while the $\mathrm{PM}_{2.5}$ effect was 1.05 (1.01-1.09). The results for $\mathrm{NO}_{2}$ were homogeneous across the studies. The large effect of $\mathrm{PM}_{2.5}$ on respiratory mortality was notable in Europe, where an effect of $8 \%$ was detected with a heterogeneity as high as $40 \%$.

The results of the pooled estimates using interquartile ranges (IQRs) as the exposure metric are presented in Table 2. The number of studies with available estimates is slightly lower than for the analysis using a fixed increment, since four of them $[16,17,25,34]$ did not provide IQRs data or figures to estimate them. The median IQRs were different for the outcomes considered and the variability of $\mathrm{NO}_{2}$ levels was greater than for $\mathrm{PM}_{2.5}$ (e.g. $14.1 \mu \mathrm{g} / \mathrm{m}^{3}$ for $\mathrm{NO}_{2}$ and $5.4 \mu \mathrm{g} / \mathrm{m}^{3}$ for $\mathrm{PM}_{2.5}$ in natural/total mortality studies). The estimates based on IQRs showed greater effects of $\mathrm{NO}_{2}$ than of $\mathrm{PM}_{2.5}$ on total mortality (6\% vs. $3 \%$ for $\left.\mathrm{PM}_{2.5}\right)$ and on cardiovascular mortality (29\% vs. $16 \%$ for $\mathrm{PM}_{2.5}$ ). The effects were, instead, similar for respiratory mortality ( $4 \%$ for both $\mathrm{NO}_{2}$ and $\mathrm{PM}_{2.5}$ ).

The results of the multi-pollutant analyses (as assessed in the original papers) are reported in supplemental Table C. Only seven studies [12, 17, 18, 20, 22, 24, 32], among those included in the 
meta-analysis, performed bi-pollutant analyses, including Gehring [32], Jerrett [22] and Lipfert [24] who analysed the $\mathrm{NO}_{2}$ effects only with a traffic indicator. Cao [17] in Asia and Cesaroni [12] in Europe found no change in the effects of $\mathrm{NO}_{2}$ on total mortality when it was analysed together with PM, whereas the reduced effect observed by Hart [20] in the U.S.A. relates to a model including three pollutants $\left(\mathrm{NO}_{2}, \mathrm{PM}_{10}\right.$ and $\left.\mathrm{SO}_{2}\right)$. Among the three studies which again analysed $\mathrm{NO}_{2}$ and $\mathrm{PM}$ effects on cardio-vascular mortality (Cao [17] in Asia, Gan [18] in Canada and Hart [20] in the U.S.A), two $[18,20]$ found independent effects of $\mathrm{NO}_{2}$. Three authors analysed $\mathrm{NO}_{2}$ effects with a traffic indicator: Lipfert [24] in the U.S.A. and Jerret [22] in Toronto found reduced effects of $\mathrm{NO}_{2}$ on total and cardiovascular mortality, but no change was reported in the European study [32].

\section{DISCUSSION}

We found similar risk estimates for total mortality in studies investigating the long-term effects of both $\mathrm{NO}_{2}$ and $\mathrm{PM}_{2.5}$ (4\% increase vs. 5\%, respectively) using an exposure metric of $10 \mu \mathrm{g} / \mathrm{m}^{3}$. In Europe, there was a $7 \%$ increase of total mortality for both $\mathrm{NO}_{2}$ and fine particles. Hoek et al. [5] in their recent review found a worldwide pooled estimate of 5.5\% $(95 \% \mathrm{CI}=3.1-8.0 \%)$ for $\mathrm{NO}_{2}$; their study, unlike the present one, included estimates from studies that did not analyse particles. We found greater effects of $\mathrm{PM}_{2.5}$ than of $\mathrm{NO}_{2}$ for cardiovascular (20\% vs. $\left.13 \%\right)$ and respiratory (5\% vs. $2 \%$ ), per $10 \mu \mathrm{g} / \mathrm{m}^{3}$ of pollutants. Per interquartile range, estimates for cardiovascular mortality were larger for $\mathrm{NO}_{2}$ than for $\mathrm{PM}_{2.5}(29 \%$ vs. $16 \%)$. In the recent review by Hoek, $\mathrm{NO}_{2}$ effects ranging from $3 \%$ to $36 \%$ per $10 \mu \mathrm{g} / \mathrm{m}^{3}$ have been reported for cardiovascular mortality in European cohorts as well as an effect of $12 \%$ for respiratory mortality [5]. All our estimates were rather heterogeneous, with the sole exception of respiratory mortality. In the few studies with bi-pollutant models, the effects of $\mathrm{NO}_{2}$ and particles (of different sizes) seemed independent.

The comparison of studies carried out in worldwide geographical areas is beset by many challenges. The methods used to assess exposure play an important role. The $\mathrm{NO}_{2}$ levels observed in the U.S.A., Asia and Europe are very similar. In contrast, $\mathrm{PM}_{2.5}$ levels are lower in the U.S.A. than in Europe, 
and both are much lower than the Asian levels. The methods used in assessing exposure (such as dispersion modelling, land use regression models and inverse distance weighting), as well as the methods used in pollution monitoring (such as the number and location of fixed monitors as well as the daily sampling intervals) could all influence the quality of the exposure assessment causing a possible differential misclassification. However, since lower levels of $\mathrm{PM}_{2.5}$ in the U.S.A. produced effects on total mortality comparable to those observed in Europe, a different toxicity of the fine particle components between areas could also play a role.

The length of the exposure (or modelling) period was not always taken sufficiently into consideration. This is an important drawback when risk estimates for long-term mortality are to be compared. The length of exposure assessment ranged from one [21, 23] to 12 years [15] when reported as measured levels of pollutants, and from 2-40 years when estimated by means of models (mainly dispersion or LUR models). In addition, length of exposure is mostly assessed on the basis of length of residence, assuming that the pollution levels monitored in a shorter time than residence period represents the real exposure of the whole residence period. Only few investigations have addressed the long-term stability of the spatial contrasts in the exposures used in the epidemiological analyses. [35,36]

Latency differs among studies, often not consistently with the study design. Three studies [15, 17, 19] had an overlap between the exposure and the follow-up periods, others started the follow-up in the same year the pollutant exposure was assessed [24,28], though they prolonged the follow-up for up to 30 years. In a few studies $[12,20,21,34]$ exposure was assessed in a few years included within the follow-up or even after the follow-up [22]. Finally, eight studies [16, 18, 23, 25, 26, 27, 32, 33] carried out a follow-up from at least one year after the assessed exposure for up to 6-20 years thereafter. Therefore, the differences in assessing the temporal relationship between exposure and outcome across the studies represent a possible challenge for the interpretation of the results. Doubts could rise also when the exposure has been assessed after starting follow-up, since strong 
assumptions were necessary about the length of residence and the corresponding levels of pollutants.

Some methodological choices in carrying out the meta-analysis need to be discussed. The first relevant point for the interpretation of the results is the reliability of the meta-analytic estimates by geographic area. The European and North American estimates for total and cardiovascular mortality, as well as the European estimates for respiratory mortality, are more reliable than Asian estimates because at least four papers are included. However, the heterogeneity across the studies affects the reliability $[10,38]$ of the estimates of total and cardiovascular mortality, in all areas and for both pollutants. The sole exception is the effect of $\mathrm{NO}_{2}$ on respiratory mortality in both Europe and the U.S.A. (with three studies). It should be noted that the heterogeneity for cardiovascular mortality was strongly reduced when we restricted to studies with a better quality of exposure assessment and evaluating the entire population and not at at-risk groups [37].

A second methodological point for the interpretation of results is related with the pollutant exposure metric for analysing the effects of different pollutants. Using a fixed increase of $10 \mu \mathrm{g} / \mathrm{m}^{3} \mathrm{in}$ pollutant levels makes it possible to compare the effects of a single pollutant across different studies and different countries. In contrast, if one wishes to compare the effects of two or more pollutants, one needs another metric which takes into account the different distributions of pollutant levels. A pollutant with a broader exposure distribution will show smaller effect estimates per unit increase than a pollutant with a less wide exposure distribution in the same population. The additional metaanalyses we performed using the IQRs of $\mathrm{NO}_{2}$ and $\mathrm{PM}_{2.5}$ as the exposure metric show that the $\mathrm{NO}_{2}$ effects on mortality are larger than those of $\mathrm{PM}_{2.5}$, at least for total and cardiovascular mortality.

There is obviously a need for caution in drawing conclusions about the independence of $\mathrm{NO}_{2}$ effects from $\mathrm{PM}_{2.5}$ effects from the multi-pollutant models. First, not all countries were included (e.g. Asia was less represented in this analysis). Second, the high correlation between $\mathrm{NO}_{2}$ and $\mathrm{PM}_{2.5}$ (around 
0.7-0.8) in these studies still suggests the possibility that the $\mathrm{NO}_{2}$ effects could be due in part to confounding from PM. Third, uncertainty is also due to the limited number of bi-pollutant estimates available. It should be noted, however, that only minimal difference between the single-pollutant and the multi-pollutant results for $\mathrm{NO}_{2}$ were found.

Finally, though this study being a meta-analysis, cannot respond exhaustively to the causality question about $\mathrm{NO}_{2}$, it contributes to the scientific debate on this topic because it assesses the respective role of $\mathrm{NO}_{2}$ and $\mathrm{PM}_{2.5}$ as they emerge from prospective studies [38] and provides a pooled effect estimate to be used for future impact health assessment.

In conclusion, the magnitude of the long-term effects of nitrogen dioxide on mortality is at least as important as that of $\mathrm{PM}_{2.5}$. These results hold when using both $10 \mu \mathrm{g} / \mathrm{m}^{3}$ or IQR as the metric of choice. The results of the multi-pollutant models suggest that the role of nitrogen dioxide is independent of that of particles. All these elements may be useful when discussing the causality issue for $\mathrm{NO}_{2}$. Moreover, $\mathrm{NO}_{2}$ is the only widely regulated pollutant (apart from carbon monoxide) that indicates exposure to combustion pollution. Health impact assessments relying only on $\mathrm{PM}_{2.5}$, and not considering $\mathrm{NO}_{2}$, would be neglecting an important source of the adverse effects of today's pollution mixture. 


\section{ACKNOWLEDGEMENTS}

We thank Karen Christenfeld (freelance medical editor; Rome) for editorial revision and Simona

Ricci (Dept of Epidemiology, Regional Health System of Lazio, Rome) for her help with the figures. 


\section{REFERENCES}

1. WHO Europe. Air quality guidelines for particulate matter, ozone, nitrogen dioxide and sulfur dioxide. Global update 2005. World Health Organization, 2006.

2. Eisner MD, Anthonisen N, Coultas D, Kuenzli N, Perez-Padilla R, Postma D, Romieu I, Silverman EK, Balmes JR; Committee on Nonsmoking COPD, Environmental and Occupational Health Assembly. An official American Thoracic Society public policy statement: Novel risk factors and the global burden of chronic obstructive pulmonary disease. Am J Respir Crit Care Med. 2010; 182: 693-718.

3. HEI Panel on the Health Effects of Traffic-Related Air Pollution. Traffic-related air pollution: a critical review of the literature on emissions, exposure, and health effects. HEI Special Report 17. Health Effect Institute, Boston MA, 2010.

4. Review of evidence on health aspects of air pollution- REVIHAAP project: Final Technical Report [http://www.euro.who.int/en/what-we-do/health-topics/environment-and-health/airquality/publications/2013/]

5. Hoek G, Krishnan RM, Beelen R, Peters A, Ostro B, Brunekreef B, Kaufman J. Long-term air pollution exposure and cardio-respiratory mortality: a review. Environ Res 2013, 12:43 doi:10.1186/1476-069X-12-43.

6. Environmental Protection Agency. Revision to the guideline on air quality models: adoption of a preferred general purpose (Flat and Complex Terrain) dispersion model and other revisions; Federal Register. 2005; vol.70 (No.216).

7. Le Tertre A, Medina S, Samoli E, Forsberg B, Michelozzi P, Boumghar A, Vonk JM, Bellini A, Atkinson R, Ayres JG, Sunyer J, Schwartz J, Katsouyanni K. Short-term effects of particulate air pollution on cardiovascular diseases in eight European cities. J Epidemiol Community Health 2002;56:773-779. 
8. Peters, Annette, Susanne Breitner, Josef Cyrys, Matthias Stölzel, Mike Pitz, Gabriele Wölke, Joachim Heinrich, Wolfgang Kreyling, Helmut Küchenhoff, and H.-Erich Wichmann. The Influence of Improved Air Quality on Mortality Risks in Erfurt, Germany. Appendix B.

Correlations and Ratios between Pollutants on an Annual Basis. HEI Research Report 137. Health Effect Institute, Boston MA, 2009.

9. Brunekreef, Bert, Rob Beelen, Gerard Hoek, Leo Schouten, Sandra Bausch-Goldbohm, Paul Fischer, Ben Armstrong, Edward Hughes, Michael Jerrett, and Piet van den Brandt. Effects of Long-Term Exposure to Traffic-Related Air Pollution on Respiratory and Cardiovascular Mortality in the Netherlands: The NLCS-AIR Study. HEI Research Report 139. Health Effect Institute, Boston MA, 2009.

10. Egger M, Smith GD, Altman D. Systematic Reviews in Health Care: Meta-Analysis in Context by BMJ publishing group, 2001

11. Higgins JPT, Thompson SG, Deeks JJ, Altman DG. Measuring inconsistency in meta-analyses. BMJ 2003;327:557-60

12. Cesaroni G, Badaloni C, Gariazzo C, Stafoggia M, Sozzi R, Davoli M, Forastiere F. Long-term exposure to urban air pollution and mortality in a cohort of more than a million adults in Rome. Environ Health Perspect 2013; 121: 324-331. doi: 10.1289/ehp.1205862.

13. Heinrich J, Thiering E, Rzehak P, Krämer U, Hochadel M, Rauchfuss KM, Gehring U, Wichmann HE. Long-term exposure to $\mathrm{NO}_{2}$ and PM10 and all-cause and cause-specific mortality in a prospective cohort of women. Occup Environ Med. 2013; 70: 179-186.

14. Dong GH, Zhang P, Sun B, Zhang L, Chen X, Ma N, Yu F, Guo H, Huang H, Lee YL, Tang N, Chen J. Long-Term Exposure to Ambient Air Pollution and Respiratory Disease Mortality in Shenyang, China: A 12-Year Population-Based Retrospective Cohort Study. Respiration 2012; 84: $360-368$. 
15. Zhang P, Dong G, Sun B, Zhang L, Chen X, Ma N, Yu F, Guo H, Huang H, Lee YL, Tang N, Chen J. Long-term exposure to ambient air pollution and mortality due to cardiovascular disease and cerebrovascular disease in Shenyang, China. PLoS One 2011; 6 (6): e20827.

16. Katanoda K, Sobue T, Satoh H, Tajima K, Suzuki T, Nakatsuka H, Takezaki T, Nakayama T, Nitta H, Tanabe K, Tominaga S. An association between long-term exposure to ambient air pollution and mortality from lung cancer and respiratory diseases in Japan. J Epidemiol 2011; 21: 132-143.

17. Cao J, Yang C, Li J, Chen R, Chen B, Gu D, Kan H. Association between long-term exposure to outdoor air pollution and mortality in China: a cohort study. J Hazard Mater 2011; 186: 1594-1600.

18. Gan WQ, Koehoorn M, Davies HW, Demers PA, Tamburic L, Brauer M.Long-term exposure to traffic-related air pollution and the risk of coronary heart disease hospitalization and mortality. Environ Health Perspect 2011; 119: 501-507.

19. Lipsett MJ, Ostro BD, Reynolds P, Goldberg D, Hertz A, Jerrett M, Smith DF, Garcia C, Chang ET, Bernstein L. Long-Term Exposure to Air Pollution and Cardiorespiratory Disease in the California Teachers Study Cohort. Am J Respir Crit Care Med 2011; 184: 828-835.

20. Hart JE, Garshick E, Dockery DW, Smith TJ, Ryan L, Laden F. Long-term ambient multipollutant exposures and mortality. Am J Respir Crit Care Med 2011; 183: 73-78.

21. Maheswaran R, Pearson T, Smeeton NC, Beevers SD, Campbell MJ, Wolfe CD. Impact of outdoor air pollution on survival after stroke: population-based cohort study. Stroke 2010; 41: 869-877.

22. Jerrett M, Finkelstein MM, Brook JR, Arain MA, Kanaroglou P, Stieb DM, Gilbert NL, Verma D, Finkelstein N, Chapman KR, Sears MR. A cohort study of traffic-related air pollution and mortality in Toronto, Ontario, Canada. Environ Health Perspect 2009; 117: 772-777.

23. Krewski D, Jerrett M, Burnett RT, Ma R, Hughes E, Shi Y, Turner MC, Pope CA 3rd, Thurston G, Calle EE, Thun MJ. Extended follow-up and spatial analysis of the American Cancer 
Society study linking particulate air pollution and mortality. Health Effects Institute, Boston, Massachusetts 2009; HEI Research Report 140, 5-114. www. healtheffects.org

24. Lipfert FW, Wyzga RE, Baty JD, Miller JP. Air pollution and survival within the Washington University-EPRI Veterans cohort: Risks based on modeled estimates of ambient levels of hazardous and criteria air pollutants. J Air Waste Manage Assoc 2009; 59: 473-489.

25. Rosenlund M, Bellander T, Nordquist T, Alfredsson L. Traffic-generated air pollution and myocardial infarction. Epidemiology 2009; 20: 265-271.

26. Beelen R, Hoek G, van den Brandt PA, Goldbohm RA, Fischer P, Schouten LJ, Jerrett M, Hughes E, Armstrong B, Brunekreef B. Long-term effects of traffic-related air pollution on mortality in a Dutch cohort (NLCS-AIR Study). Environ Health Perspect 2008; 116: 196-202.

27. Schikowski T, Sugiri D, Ranft U, Gehring U, Heinrich J, Wichmann HE, Krämer U. Does respiratory health contribute to the effects of long-term air pollution exposure on cardiovascular mortality? Respir Res 2007; 8: 20 doi:10.1186/I465-9921-8-20

28. Naess O, Nafstad P, Aamodt G, Claussen B, Rosland P. Relation between concentration of air pollution and cause-specific mortality: four-year exposures to nitrogen dioxide and particulate matter pollutants in 470 neighbourhoods in Oslo, Norway. Am J Epidemiol 2007; 165: 435-443

29. Rosenlund M, Berglind N, Pershagen G, Hallqvist J, Jonson T, Bellander T. Long-term exposure to urban air pollution and myocardial infarction. Epidemiology 2006; 17: 383-390.

30. Lipfert FW, Baty JD, Miller JP, Wyzga RE. $\mathrm{PM}_{2.5}$ constituents and related air quality variables as predictors of survival in a cohort of U.S. military veterans. Inhal Toxicol 2006; 18: 645-657.

31. Lipfert FW, Wyzga RE, Baty JD, Miller JP. Traffic density as a surrogate measure of environmental exposures in studies of air pollution health effects: long-term mortality in a cohort of US veterans. Atmospheric Environment 2006; 40: 154-169.

32. Gehring U, Heinrich J, Krämer U, Grote V, Hochadel M, Sugiri D, Kraft M, Rauchfuss K, Eberwein HG, Wichmann HE. Long-term exposure to ambient air pollution and cardiopulmonary mortality in womenEpidemiology 2006; 17: 545-551. 
33. Chen LH, Knutsen SF, Shavlik D, Beeson WL, Petersen F, Ghamsary M, Abbey D. The association between fatal coronary heart disease and ambient particulate air pollution: are females at greater risk? Environ Health Perspect 2005; 113: 1723-1729.

34. Filleul L, Rondeau V, Vandentorren S, Le Moual N, Cantagrel A, Annesi Maesano I, Charpin D, Declercq C, Neukirch F, Paris C, Vervloet D, Brochard P, Tessier JF, Kauffmann F, Baldi I, Twenty five year mortality and air pollution: results from the French PAARC survey. Occup Environ Med 2005; 62: 453-460.

35. Eeftens M, Beelen R, Fischer P, Brunekreef B, 494 Meliefste K, Hoek G. Stability of measured and modelled spatial contrasts in $\mathrm{NO}_{2}$ over time. Occup Environ Med 2011; 68: 765-770.

36. Cesaroni G, Porta D, Badaloni C, Stafoggia M, Eeftens M, Meliefste K, Nitrogen dioxide levels estimated from land use regression models several years apart and association with mortality in a large cohort study. Environmental Health: A Global Access Science Source 2012; 11(1).

37. ST Brookes ST, Whitley E, Peters TJ, Mulheran PA, Egger M, Smith GD. Subgroup analyses in randomized controlled trials: quantifying the risks of false-positives and false-negatives. Health Technology Assessment 2001; Vol. 5: No. 33

38. Weed DL. Interpreting epidemiological evidence: how meta-analysis and causal inference methods are related. Int J Epidemiol 2000; 29:387-390. 


\section{Figures titles and legends}

FIGURE 1. RELATIVE RISKS OF NATURAL MORTALITY WITH INCREASING CHRONIC EXPOSURE TO $\mathrm{NO}_{2}$. SUBTITLE OF FOREST PLOT $=$ RR of natural mortality for $10 \mu \mathrm{g} / \mathrm{m}^{3} \mathrm{NO}_{2}$ increase

FIGURE 2. RELATIVE RISKS OF CARDIOVASCULAR MORTALITY WITH INCREASING CHRONIC EXPOSURE $\mathrm{TO} \mathrm{NO}_{2}$.

SUBTITLE OF FOREST PLOT $=$ RR of cardiovascular mortality for $10 \mu \mathrm{g} / \mathrm{m}^{3} \mathrm{NO}_{2}$ increase

FIGURE 3. RELATIVE RISKS OF RESPIRATORY MORTALITY WITH INCREASING CHRONIC EXPOSURE TO $\mathrm{NO}_{2}$.

SUBTITLE OF FOREST PLOT $=$ RR of respiratory mortality for $10 \mu \mathrm{g} / \mathrm{m}^{3} \mathrm{NO}_{2}$ increase 
Figure 1

\begin{tabular}{|c|c|c|}
\hline & study & \\
\hline Asia & Cao & 2011 \\
\hline & Lipsett & 2011 \\
\hline & Hart & 2011 \\
\hline America & Jerret & 2009 \\
\hline & Krewski & 2009 \\
\hline & Lipfert & 2009 \\
\hline & Cesaroni & 2013 \\
\hline & Heinrich & 2012 \\
\hline Furnos & Maheswaran & 2010 \\
\hline Luiver & Beelen & 2008 \\
\hline & Gehring & 2006 \\
\hline & Filleul & 2005 \\
\hline & Combined & \\
\hline
\end{tabular}

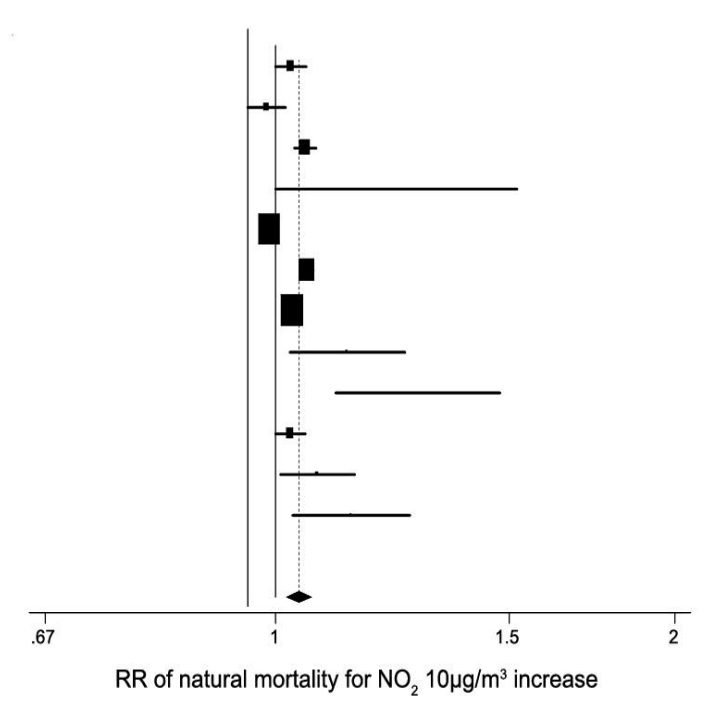

$\begin{array}{ccc}\text { weights \% } & \text { RR } & 95 \% \text { Cl } \\ 11.20 & 1.03 & 1.00-1.05 \\ 10.27 & 0.98 & 0.95-1.02 \\ 12.19 & 1.05 & 1.03-1.07 \\ 1.00 & 1.23 & 1.00-1.52 \\ 13.03 & 0.99 & 0.98-1.00 \\ 12.77 & 1.06 & 1.04-1.07 \\ 13.05 & 1.03 & 1.02-1.04 \\ 3.52 & 1.13 & 1.02-1.25 \\ 2.00 & 1.28 & 1.11-1.48 \\ 11.31 & 1.03 & 1.00-1.05 \\ 6.22 & 1.08 & 1.01-1.15 \\ 3.44 & 1.14 & 1.03-1.26 \\ & & \\ & 1.04 & 1.02-1.06\end{array}$

$\begin{array}{lll}\text { Test for heterogeneity: } & x^{2}=102.28 & d l=11 \\ & p=0.001 & l^{2}=89 \% \\ \text { Test for overall effect: } & z=3.632 & p=0.001\end{array}$

Figure 2

\begin{tabular}{|c|c|c|}
\hline & study & \\
\hline Asia & Zang & 2011 \\
\hline nota & Cao & 2011 \\
\hline & Gan & 2011 \\
\hline & Lipset & 2011 \\
\hline & Hart & 2011 \\
\hline America & Jerret & 2009 \\
\hline & Krewski & 2009 \\
\hline & Chen (men) & 2005 \\
\hline & Chen (women) & 2005 \\
\hline & Cesaroni & 2013 \\
\hline & Heinrich & 2012 \\
\hline & Rosenlund & 2009 \\
\hline & Beelen & 2008 \\
\hline Europe & Schikowski & 2007 \\
\hline & Naess (men) & 2007 \\
\hline & Naess (women) & 2007 \\
\hline & Gehring & 2006 \\
\hline & Filleul & 2005 \\
\hline
\end{tabular}

Combined (n. 18)

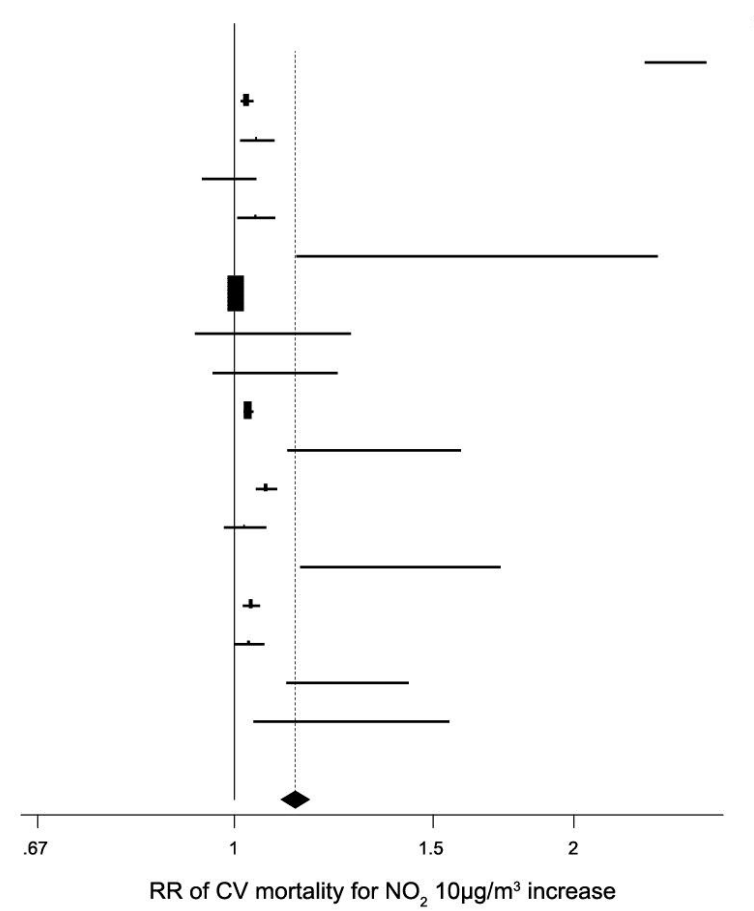

weights

5.33

$6.23 \quad 1.03$

$5.95 \quad 1.05$

$21.79 \quad 0.99$

$5.88 \quad 1.05$

$0.88 \quad 1.64$

$6.27 \quad 1.01$

$2.94 \quad 1.08$

$3.62 \quad 1.09$

$6.25 \quad 1.03$

$2.60 \quad 1.33$

$6.15 \quad 1.07$

$5.79 \quad 1.02$

$2.18 \quad 1.4$

$6.19 \quad 1.04$

$6.01 \quad 1.03$

$3.70 \quad 1.26$

$2.25 \quad 1.27$

1.02
$95 \% \mathrm{Cl}$

$2.31-2.62$

$1.01-1.04$

$1.01-1.08$

$0.94-1.05$

$1.01-1.09$

$1.14-2.37$

$1.00-1.01$

$0.92-1.27$

$0.96-1.24$

$1.02-1.04$

$1.11-1.59$

$1.05-1.09$

$0.98-1.07$

$1.14-1.72$

$1.02-1.05$

$1.00-1.06$

$1.11-1.43$

$1.04-1.55$

$1.001-1.04$

$\begin{array}{lll}\text { Test for heterogeneity: } & x^{2}=853.532 & \mathrm{dl}=17 \\ & \mathrm{p}=0.001 & \mathrm{I}^{2}=98 \% \\ \text { Test for overall effect: } & \mathrm{z}=6.010 & \mathrm{p}=0.001\end{array}$ 
Figure 3

\begin{tabular}{|c|c|}
\hline & study \\
\hline & Katanoda \\
\hline Asla & $\mathrm{Cao}$ \\
\hline & Lipsett \\
\hline America & Hart \\
\hline & Jerret \\
\hline & Cesaroni \\
\hline Furnne & Beelen \\
\hline & Naess (men) \\
\hline & Naess (wome \\
\hline
\end{tabular}

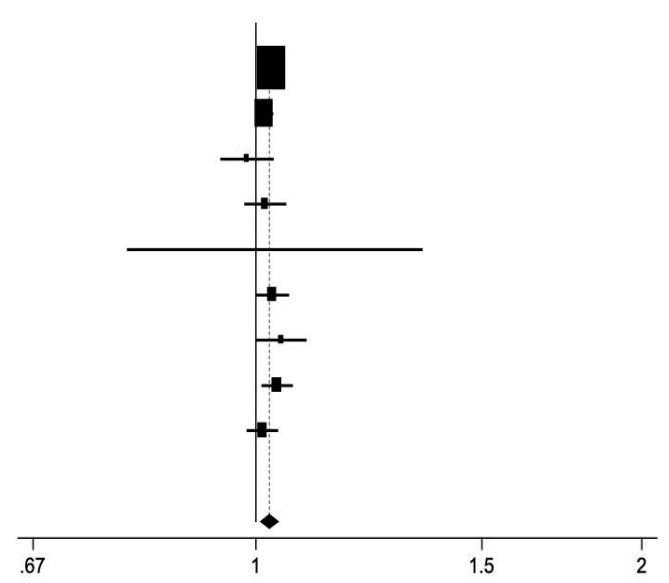

weights \% $\quad$ RR $\quad 95 \% \mathrm{Cl}$

$49.93 \quad 1.03 \quad 1.02-1.04$

$21.26 \quad 1.01 \quad 1.00-1.03$

$2.35 \quad 0.98 \quad 0.94-1.03$

$3.82 \quad 1.02 \quad 0.98-1.06$

$0.08 \quad 1.03 \quad 0.79-1.35$

$6.25 \quad 1.03 \quad 1.00-1.06$

$2.63 \quad 1.05 \quad 1.00-1.1$

$6.84 \quad 1.04 \quad 1.01-1.07$

$6.85 \quad 1.01 \quad 0.98-1.04$

Combined (n. 9)

$\mathrm{RR}$ of respiratory mortality for $\mathrm{NO}_{2} 10 \mu \mathrm{g} / \mathrm{m}^{3}$ increase

$\begin{array}{cll}\text { Test for heterogeneity: } & x^{2}=7.383 & d l=8 \\ & p=0.496 & l^{2}=0 \% \\ \text { Test for overall effect: } & z=6.362 & p=0.001\end{array}$


Table 1. Pooled* effects of $\mathrm{NO}_{2}$ and $\mathrm{PM}_{2.5}\left(\right.$ per $\left.10 \mu \mathrm{g} / \mathrm{m}^{3}\right)$ on natural and cause-specific mortality by region of the world Total or natural mortality

Cardiovascular mortality

Respiratory mortality

\begin{tabular}{|c|c|c|c|c|c|c|c|c|c|c|c|c|c|c|c|}
\hline & $\begin{array}{c}\mathrm{N} \\
\text { studies }\end{array}$ & $\mathrm{RR}$ & \multicolumn{2}{|c|}{$95 \% \mathrm{Cls}$} & $1^{2}$ & $\begin{array}{c}\mathrm{N} \\
\text { studies }\end{array}$ & $\mathrm{RR}$ & \multicolumn{2}{|c|}{$95 \% \mathrm{Cls}$} & $\mathrm{I}^{2}$ & $\begin{array}{c}\mathrm{N} \\
\text { studies }\end{array}$ & $\mathrm{RR}$ & \multicolumn{2}{|c|}{$95 \% \mathrm{Cls}$} & $1^{2}$ \\
\hline \multicolumn{16}{|l|}{$\mathrm{NO}_{2}\left(10 \mu \mathrm{g} / \mathrm{m}^{3}\right)$} \\
\hline All countries & 12 & 1.041 & 1.019 & 1.064 & $89 \%$ & $18 \S^{\circ}$ & 1.133 & 1.088 & 1.180 & $98 \%$ & $9^{\circ} \#++$ & 1.024 & 1.017 & 1.032 & $0 \%$ \\
\hline Asia & 1 & 1.020 & 1.000 & 1.030 & & 2 & 1.588 & 0.675 & 3.740 & $99 \%$ & 2 & 1.023 & 1.010 & 1.036 & $47 \%$ \\
\hline America & 5 & 1.027 & 0.987 & 1.069 & $95 \%$ & 7 & 1.031 & 0.999 & 1.065 & $67 \%$ & 3 & 1.005 & 0.975 & 1.035 & $0 \%$ \\
\hline Europe & 6 & 1.066 & 1.029 & 1.104 & $72 \%$ & 9 & 1.059 & 1.032 & 1.086 & $79 \%$ & 4 & 1.029 & 1.013 & 1.045 & $0 \%$ \\
\hline \multicolumn{16}{|c|}{$\mathrm{PM}_{2.5}\left(10 \mu \mathrm{g} / \mathrm{m}^{3}\right)$} \\
\hline All countries & $11+$ & 1.045 & 1.007 & 1.088 & $87 \%$ & $17 \S^{\circ}+$ & 1.196 & 1.091 & 1.31 & $98 \%$ & $8^{\circ} \#++,+$ & 1.050 & 1.009 & 1.094 & $61 \%$ \\
\hline Asia & 1 & 1.000 & 0.980 & 1.020 & & 2 & 1.380 & 0.761 & 2.502 & $99 \%$ & 2 & 1.034 & 0.943 & 1.134 & $50 \%$ \\
\hline America & 4 & 1.047 & 1.035 & 1.106 & $83 \%$ & 6 & 1.047 & 0.992 & 1.106 & $71 \%$ & 2 & 1.046 & 0.990 & 1.104 & $0 \%$ \\
\hline Europe & 6 & 1.071 & 1.021 & 1.124 & $62 \%$ & 9 & 1.188 & 1.091 & 1.295 & $42 \%$ & 4 & 1.075 & 1.009 & 1.146 & $40 \%$ \\
\hline
\end{tabular}

* results from random-effects meta-analyses $\S$ two studies (one from America [33] and one from Europe [28) were included twice with separate groups of men and women. ${ }^{\circ}$ Four studies (one from America [23] and three from Europe [13, 32, 34]) estimated cardiopulmonary mortality as a whole. They were included in the pooled CV mortality estimate and excluded from the pooled respiratory mortality estimate. \# One study from China [14] was excluded because it estimated lung cancer together with respiratory mortality. '++ one study from Europe [28] was included twice with separate estimates for men and women. + one study from the USA [22] cannot be included because it did not show the PM effect estimates. 
Table 2. Pooled* effects of NO2 and PM $\left(10 \mu \mathrm{g} / \mathrm{m}^{3}\right.$ and IQR $\left.\mu \mathrm{g} / \mathrm{m}^{3}\right)$ on natural and specific-cause mortality

\begin{tabular}{|c|c|c|c|c|c|c|c|c|c|c|c|c|c|c|c|c|c|}
\hline \multirow[b]{3}{*}{$\mathrm{NO}_{2}(10 \mu \mathrm{g} / \mathrm{m} 3)$} & \multicolumn{5}{|c|}{ total or natural mortality } & & \multicolumn{5}{|c|}{ cardio-vascular mortality } & \multicolumn{6}{|c|}{ respiratory mortality } \\
\hline & \multirow{2}{*}{$\begin{array}{c}\begin{array}{c}\mathrm{N} \\
\text { studies }\end{array} \\
10^{* *}\end{array}$} & \multirow{2}{*}{$\frac{\mathrm{RR}}{1.040}$} & \multicolumn{2}{|c|}{$95 \% \mathrm{Cls}$} & \multirow{2}{*}{$\frac{1^{2}}{91 \%}$} & & \multirow{2}{*}{$\begin{array}{c}\mathbf{N} \\
\text { studies }\end{array}$} & \multirow{2}{*}{$\frac{\mathrm{RR}}{1.152}$} & \multicolumn{2}{|c|}{$95 \% \mathrm{Cls}$} & \multirow{2}{*}{$\frac{1^{2}}{98 \%}$} & \multirow[b]{2}{*}{$\mathrm{NO}_{2}(10 \mu \mathrm{g} / \mathrm{m} 3)$} & \multirow{2}{*}{$\begin{array}{c}\mathbf{N} \\
\text { studies }\end{array}$} & \multirow{2}{*}{$\frac{\mathrm{RR}}{1.024}$} & \multicolumn{2}{|c|}{$95 \% \mathrm{Cls}$} & \multirow{2}{*}{$\frac{1^{2}}{0 \%}$} \\
\hline & & & 1.015 & 1.065 & & $\mathrm{NO}_{2}(10 \mu \mathrm{g} / \mathrm{m} 3)$ & & & 1.094 & 1.213 & & & & & 1.010 & 1.038 & \\
\hline $\mathrm{NO}_{2}(14.6 \mu \mathrm{g} / \mathrm{m} 3$ & & 1.059 & 1.022 & 1.096 & & $\mathrm{NO}_{2}(17.9 \mu \mathrm{g} / \mathrm{m} 3$ & & 1.288 & 1.174 & 1.413 & & $\mathrm{NO}_{2}(15.0 \mu \mathrm{g} / \mathrm{m} 3$ & & 1.036 & 1.015 & 1.058 & \\
\hline $\mathrm{PM}_{2.5}(10 \mu \mathrm{g} / \mathrm{m} 3)$ & $9 * *+$ & 1.050 & 1.024 & 1.078 & $78 \%$ & $\mathrm{PM}_{2.5}\left(10 \mu \mathrm{g} / \mathrm{m}^{3}\right.$ & $14^{\wedge} \S^{\circ}+$ & 1.228 & 1.084 & 1.39 & $98 \%$ & $\mathrm{PM}_{2.5}\left(10 \mu \mathrm{g} / \mathrm{m}^{3}\right.$ & $6 \#++,+$ & 1.062 & 1.022 & 1.104 & $11 \%$ \\
\hline $\mathrm{PM}_{2.5}\left(5.8 \mu \mathrm{g} / \mathrm{m}_{3}\right.$ & & 1.029 & 1.014 & 1.045 & & $\mathrm{PM}_{2.5}(7.0 \mu \mathrm{g} / \mathrm{m}$ & & 1.155 & 1.058 & 1.259 & & $\mathrm{PM}_{2.5}(7.0 \mu \mathrm{g} / \mathrm{r}$ & & 1.043 & 1.015 & 1.072 & \\
\hline
\end{tabular}

* random estimates. ${ }^{* *}$ two studies (Cao and Filleul) were excluded as they did not give IQR estimates or dispersion parameters to estimate them.

$\wedge$ three studies (Cao, Rosenlund and Filleul) were excluded as they did not give IQR estimates or dispersion parameters to estimate them.

$\S$ two studies (Naess, 2007 and Chen 2005) were included twice with separate groups of men and women.

- Two studies from Europe (Heinrich 2012 and Gehring 2006) estimated cardio-pulmunary mortality as a whole. They were included in the pooled

CV mortality estimate and excluded from respiratory mortality pooled es timate.

\# One study (from China (Dong, 2011)) was not included because it estimated lung cancer together with respiratory mortality.

Three studies (Katanoda, Cao and Filleul) were excluded as they did not give IQR or dispersion parameters to estimate them.

+ one study from the USA (Jerret, 2009) cannot be included as it did not show the PM effect estimates.

++ one study from Europe (Naess, 2007) was included twice with independent groups of men and women. 